\section{Promoting a standard nomenclature for genes and proteins}

Sir - The HUGO Gene Nomenclature Committee was pleased to note that Nature has, not before time, decided to be more rigorous in requiring authors to use standard nomenclature for genes and proteins (Opinion, Nature 401, 411; 1999). A growing number of journals now realize the contribution they can make to reducing confusion in the published literature and databases.

Our committee provides a searchable list of human gene symbols, including both the approved symbols and many published synonyms or aliases (www.gene.ucl. ac.uk/nomenclature). It is true that nomenclature authorities are finding it hard to keep pace with the overwhelming amount of data. However, the attitude in the research community should not be 'someone should do something', but 'what can I do?'. Scientists, journal editors, database administrators and funding bodies all need to be nomenclature-aware.

It should not be too difficult for most people to find the nomenclature authorities, and the standards and guidelines, for their areas of interest. Far too often, problems arise because editors and authors are ignorant of established standards. Authors have argued against using a previously agreed symbol when describing the same gene in a new publication "because it would detract from the novelty of their results". We have also seen journals publish papers about a "new" gene, whereas if they had contacted us we could have established that the gene had been previously described, but with a different name. Journals are in the best position to enforce nomenclature standards. Researchers are not obliged to submit data to databases, correct existing database entries, or use approved nomenclature - unless they have to do so as a requirement of journal publication.

It was suggested that databases need to do more to help standardize nomenclature. Primary sequence databases (GenBank, EMBL, DDBJ) would have a major problem enforcing standard nomenclature. The volume of data submitted to them precludes all except automated initial checks. It would be possible to check that any gene symbol in the annotation was approved, but ensuring that it was the correct symbol for that sequence would be much more complex. An incorrect, but apparently approved, gene symbol attached to a sequence record is worse than useless.

It is at the level of the secondary, curated databases that much more is being done to ensure that references, sequences and related data are linked to the approved nomenclature as well as to known aliases. Even with extensive collaboration, this labourintensive process is under considerable pressure. Recent projects, such as LocusLink at the US National Center for Biotechnology Information, are helping to improve links between related databases, and are bringing the issue of approved nomenclature to the attention of a wider community. The downside of this is more pressure on curators to deal with queries.

Funding bodies should consider whether sufficient funds are being allocated to the curation effort, as without it much effort is wasted trying to find relevant data. Julia White, Hester Wain, Elspeth Bruford, Sue Povey

HUGO Gene Nomenclature Committee,

The Galton Laboratory, University College London, 4 Stephenson Way, London NW1 2HE, UK

e-mail:nome@galton.ucl.ac.uk

\section{Sequencing challenge}

Sir - We welcome your editorial on the need to standardize gene nomenclature ${ }^{1}$. As you rightly point out, a nomenclature standardized within and between species, and well curated databases, are vital if diverse data are to be integrated.

The Mouse Genome Informatics Nomenclature Committee applauds Nature's decision to be more rigorous in requiring authors of papers to use approved nomenclature of genes and proteins. At least four genetics journals require such approval for gene symbols, and others include information on approved nomenclature in their guidelines to authors.

The 1998 "Genetic nomenclature guide" 2 contains information on the rules for genetic nomenclature in many model organisms, together with websites and contact information. We hope other journals will join the effort to encourage the use of standardized gene nomenclature.

There are numerous articles about the need for approved nomenclature ${ }^{3-6}$. And two international workshops have been held to bring together researchers on various species and gene families, pharmaceutical interests and database administrators to discuss issues pertaining to nomenclature across species and gene families, and the integration of nomenclature processes between databases ${ }^{7,8}$.

A major challenge in the coming years will be to address the nomenclature of genes identified by large-scale genomic sequencing. Ideally, genes should be given names that are not only unique, but are also portable between species, and give some indication of relationships within gene families. A third workshop, in May/June 2000 in Breckenridge, Colorado, will discuss the needs resulting from large-scale genomic sequencing efforts.

Data integration depends on the correct identification of genes and genomic segments. We continue to work with the scientific community to standardize nomenclature within the Mouse Genome Informatics (MGI) databases (http://www. informatics.jax.org/) in accordance with the Mouse Nomenclature Rules and Guidelines (http://www.informatics.jax.org/ support/nomen/). MGI curators work with corresponding authors to determine correct nomenclature before and after publication. This work is done in collaboration with nomenclature groups for human, rat and other species.

Lois J. Maltais ${ }^{\star}$, Ian Jackson $\dagger$

${ }^{*}$ Mouse Genome Database Nomenclature Coordinator, The Jackson Laboratory, 600 Main Street, Bar Harbor, Maine 04609-1500, USA

$\dagger$ International Committee on Standardized Genetic Nomenclature for Mice, MRC Human Genetics Unit, Western General Hospital, Edinburgh EH4 2XU, UK

1. Nature 401, 411 (1999).

2. Wood, R. (ed.) "Genetic nomenclature guide with information on websites" (Suppl.) Trends Genet. (1998).

3. Nature Genet. 18, 89-90 (1998).

4. White, J., Maltais, L. \& Nebert, D. Nature Genet. 18, 209 (1998).

5. http://genetics.nature.com/nomen/nomen_article.html

6. Smaglik, P. The Scientist 12, 1 \& 6 (1998).

. Blake, J. A. et al. Genomics 45, 464-468 (1997).

8. White, J. A. et al. Genomics (in the press).

\section{What's in a name?}

Sir-Your editorial on the state of gene and protein nomenclature struck a chord with those of us recently engaged in compiling the Oxford Dictionary of Biochemistry and Molecular Biology (Nature 401, 411; 1999). Formidable complexities face the groups endeavouring to bring order into the situation.

In the first place, one has to distinguish the roles of systematic names and common names. A systematic name aims to provide unambiguous information concerning some aspect of the substance described. In the case of organic chemicals, the property addressed is structure; in the case of enzymes, the enzyme reaction. Which property of a protein would be addressed in the provision of a systematic name structure, function or origin?

Whichever property is addressed, it is likely that the systematic name would be too unwieldy for everyday use, hence the need for common, or trivial, names. The current fashion for naming proteins following the convention for genes, using three letters followed by a number, proves inadequate in several ways for use as a common name, especially in that it is not descriptive, a property highly desirable in a common name.

Your proposed insistence that authors should as far as possible indicate all related 
names for the protein they are describing is indeed a step in the right direction. Tony Smith

Oxford Dictionary of Biochemistry and Molecular Biology, 46 Stanley Hill Avenue, Amersham HP7 9BB, UK

\section{Cooperative efforts around Lake Tahoe}

Sir - The proposed Round Hill facility of the Desert Research Institute in cooperation with the University of Nevada, Reno, will be complementary to the University of California at Davis facility on the California side of Lake Tahoe, and will certainly not be a "duplicate" as suggested in the News story "University confronts new rival across Lake Tahoe" (Nature 400, 806; 1999).

Our Nevada facility will focus on atmospheric, ecological and hydro-geological research on processes in the forest environments surrounding the lake, whereas most Davis work has dealt primarily with processes in the lake. The Round Hill facility will also provide a location for integration of science, management and public policy.

The planning for Round Hill has been open, with details discussed in a series of public meetings since 1997. A memorandum of understanding was signed on 11 August 1999, in which the Desert Research Institute (DRI), University of Nevada, Reno (UNR), and Davis agreed to work with federal and state agencies to develop and implement a research agenda. This is not "competition" by Nevada scientists. The atmosphere is much more cooperative than suggested by the News story.

The notion that UNR and DRI scientists are newcomers to Tahoe basin research is not true. Nevada researchers have been studying the basin's ecosystems for decades, often in collaboration with Davis scientists. The Davis Tahoe Research Group, under the leadership of Charles Goldman, has also made significant contributions to our understanding of processes within the lake.

The proposed research facilities will be of benefit on two counts. First, the ecosystem is so complex that two research centres, one in Nevada and one in California, should speed the process of tackling the lake's environmental problems. Second, the US system of research funding is based on competition so that the best research is conducted. Although we anticipate collaboration on many projects, additional scientists competing for funds will increase the quality of research in the end.

Our goal is to provide excellent science that will allow public policy-makers to define and develop effective environmental management strategies. Nevada scientists support the excellent collaborative research programme developing at Lake Tahoe, which includes faculty members from Davis as well as researchers from national and international institutions. Our combined efforts will lead to an environmental management strategy to sustain the lake's beauty for the foreseeable future.

Stephen G. Wells ${ }^{\star}$, James S. Coleman ${ }^{\star}$, Joseph N. Crowley†, Kenneth W. Hunter Jr $\dagger$ ${ }^{*}$ Desert Research Institute, 2215 Raggio Parkway, Reno, Nevada 89512-1095, USA

$\dagger$ Office of the President, University of Nevada, Reno, Nevada 89557, USA

Rex Dalton, the author of the News article, stands by his story as an accurate description of the issues and competitive situation surrounding Lake Tahoe research. - Editor, Nature

\section{Precautionary approach to risk assessment}

Sir - The meeting of the World Trade Organization (WTO), which opens on 29 November in Seattle, Washington, will be a focal point for discussions about the social, economic and environmental implications of trade. Science has been given a central role in mediating disputes about the safety and environmental impact of new technologies. Our research indicates that the WTO will need to be both more rigorous and more precautionary in its use of regulatory science if it is adequately to address issues of sustainability.

First, there is the issue of product safety. Conventional probabilistic risk assessments play an important role in WTO rulings about the safety of new products, such as genetically modified (GM) foods and hormones used in animal production [see Briefing in this issue, pages 341-345]. In contrast, 'precautionary approaches' are often thought of as deviating from sound science.

Yet current risk assessments can only characterize some of the potential outcomes of the use of new products. Precautionary approaches, by acknowledging our incomplete knowledge of possible outcomes, and addressing the huge variation in the results of risk assessments, may actually enhance the rigour of scientific assessment. We developed this argument in The Politics of GM Food: Risk, Science and Public Trust (see www.gecko.ac.uk).

Second, there is the question of burdens of proof. WTO regulations and other international trade rules increasingly assume that new products are safe until proven otherwise: the burden of proof falls heavily on those who are worried about unforeseen or untested safety and environmental issues.

The debate about the safety of the bovine somatotropin (BST) growth hormone is a recent example. It has fallen to the European Union (EU) to provide evidence to support its doubts, rather than the producer of BST to demonstrate its safety. So the burden of proof falls on the regulator rather than the proponent of the technology. We believe that the burden of proof should be re-balanced through enhanced and transparent testing of new products, similar to the current method for testing and approving drugs. Likewise, there is a need for better scientific monitoring of the effects of new technologies once in use. Hormone-disrupting chemicals exemplify the issue of inadequate monitoring.

Assuming that products are safe until proven otherwise may lead to what can be described as 'soft disasters' - large-scale health and environmental problems that emerge slowly but at high cost to society. Such disasters mostly occur because excessive faith has been placed upon limited data about the safety of a product or process, ignoring many possible eventualities where there is little or no information.

It is now generally accepted that the assessment of risk in different social contexts can produce different - but equally valid - results based in science. Alternative assumptions, for example, are often adopted in different countries, partly as a result of varying social, economic and institutional conditions. But this calls into question the WTO's apparent assumption that the application of 'sound science' will lead to a single 'scientific' answer to complex questions of risk and safety. Further, to expect a uniform pattern of associated regulatory decisions is inconsistent with the well-established insights from risk assessment.

Such a desire for single, definitive answers is likely to generate increasing tension in the WTO, and undermine public confidence in its decisions. Public confidence will be vital if the advantages of liberalized global trade are to be sustained. A more effective way forward would be to pursue these issues through a precautionary approach within multilateral environmental agreements. Liability regimes also need to be strengthened as a safety net for those affected by 'soft disasters'. In this respect, the EU's recent extension of its strict liability laws to include agricultural products is to be welcomed.

These comments are based on research carried out within the Global Environmental Change Programme of the UK Economic and Social Research Council (ESRC).

Alister Scott*, Andy Stirling, Nick Mabey, Frans Berkhout, Chris Williams, Chris Rose, Michael Jacobs, Robin GroveWhite, Ian Scoones, Melissa Leach ${ }^{*}$ Corresponding author: ESRC Global Environmental Change Programme, Mantell Building, University of Sussex, Brighton BN1 9RF, UK 